\title{
Alterações dimensionais em modelos de gessos com fraturas e colagem com cianocrilato
}

\section{Dimensional change in gypsum models with fractures and collage with cyanocrylate}

\author{
Suelen Aline de Lima Barros* \\ Lorena Soares Melo* \\ Lorenna Bastos Lima Verde Nogueira* \\ Carmem Dolores Vilarinho Soares de Moura*** \\ Walter Leal de Moura*** \\ Valdimar da Silva Valente ${ }^{* * *}$
}

\section{Resumo}

Objetivo: avaliar a precisão dimensional de modelos de gesso tipos III e IV submetidos a diversos tipos de fraturas, seguidas de colagem com cianoacrilato. Materiais e método: a amostra foi constituída por 80 modelos de gesso obtidos a partir de moldes de silicone de adição Zetalabor Platinum ${ }^{\circledR}$, provenientes de um modelo mestre em aço inox, com dois pilares. Foram formados 2 grupos ( $n$ = 40): Grupo 1-Modelos de gesso tipo III e Grupo 2-Modelos de gesso tipo IV. Cada grupo foi subdividido em: Controle $(n=10)$ Modelos de gesso sem fratura; Experimental $1(n=10)$ Modelos de gesso colados com adesivo a base de cianoacrilato SuperBonder ${ }^{\circledR}$ após fratura no espaço protético, entre os dois pilares; Experimental 2 (n $=10$ ) Modelos de gesso colados após fratura horizontal nos pilares, simulando fratura, ocorrida durante a remoção do modelo do molde; Experimental $3(n=10)$ Modelos de gesso colados após fratura simulando acidente de queda de uma bancada de laboratório. As unidades amostrais foram mensuradas com paquímetro digital. Os dados foram processados e submetidos à análise estatística (teste de Shapiro-Wilk e teste $t$ student). Resultados: os modelos de gesso fraturados e colados com cianoacrilato exibiram alterações dimensionais lineares quando comparados aos respectivos controles. Os modelos de gesso tipo III do Grupo 1, se comportaram de forma diferente, quando comparados aos modelos de gesso tipo IV do mesmo grupo. Conclusão: a colagem de pilares em modelos de gesso de prótese fixa, sem padronização, põe em risco a precisão dimensional desses.

Palavras-chave: Gesso. Prótese Dentária. Cianoacrilato.

\section{Introdução}

Os modelos de gesso utilizados na prática odontológica podem ser acometidos por fraturas durante a sua manipulação em consultório e laboratório de prótese. As fraturas dos modelos de gesso utilizados para confecção de próteses fixas ocorrem, com mais frequência, durante a remoção do modelo, especialmente quando o material de moldagem oferece resistência e/ou quando os preparos dentários são longos e finos ${ }^{1}$.

Diante da necessidade de colagem dos fragmentos, estudo anterior avaliou os efeitos desse procedimento e os autores sugeriram que é possível realizá-lo na prática laboratorial, sem afetar a precisão final da prótese ${ }^{2}$.

$\mathrm{O}$ adesivo de cianoacrilato tem sido utilizado para colar fragmentos de gesso com resultados satisfatórios ${ }^{3}$. Também tem sido usado para melhorar as propriedades de modelos de gesso através da aplicação de uma fina camada sobre o gesso, aumentando assim, a resistência à fratura e abrasã $0^{4,5}$. Reduz ainda a absorção de água ${ }^{6}$ e quando aplicado no troquel de gesso preserva a margem do preparo $^{4,6}$. Além disso, os adesivos à base de cianoacrilato são simples de usar, polimerizam ao reagir 
com a umidade do ar e, comercialmente, possuem baixo custo.

O cianoacrilato também apresenta propriedade antimicrobiana $^{7}$ e tem sido aplicado em suturas da mucosa oral, podendo simplificar o procedimento cirúrgico em áreas inacessíveis para suturar, pois estabiliza e fixa as superfícies através de hemostasia ${ }^{8}$. Na dentística, pode ser usado como protetor superficial de restaurações de cimento de ionômero de vi$\mathrm{dro}^{9} \mathrm{e}$ como coadjuvante do isolamento absoluto ${ }^{10,11}$.

O objetivo do presente estudo foi avaliar a precisão dimensional de modelos de gesso tipos III e IV submetidos a diversos tipos de fraturas, seguidas de colagem com adesivo à base de Cianoacrilato.

\section{Materiais e método}

A amostra foi constituída por 80 modelos de gesso obtidos a partir de moldes de silicone de adição Zetalabor Platinum ${ }^{\circledR}$ (Labordental, São Paulo, Brasil), provenientes de um modelo mestre em aço inox, com dois pilares (simulando preparos de um pré-molar e molar) separados por um espaço protético (Fig. 1).

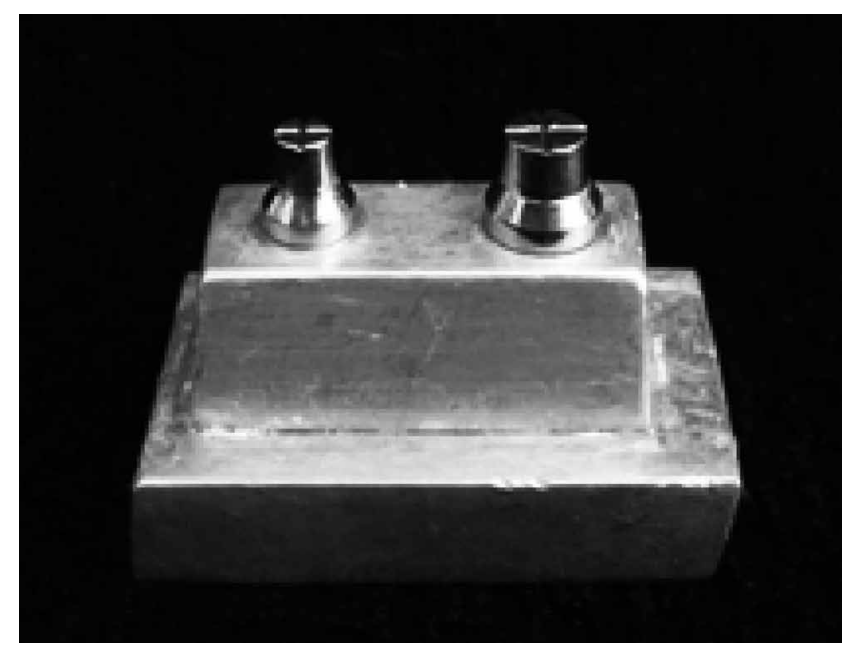

Figura 1 - Modelo mestre em aço inox

A amostra foi dividida em dois grupos $(n=40)$ : Grupo 1) Modelos de gesso tipo III (Gesso pedra extra duro Tipo III ${ }^{\circledR}$, Rutenium, Rio de Janeiro, Brasil) e Grupo 2) Modelos de gesso tipo IV (Durone ${ }^{\circledR}$, Dentsply Latin America, Rio de Janeiro, Brasil). Cada grupo foi subdividido em: Controle $(n=10)$ Modelos de gesso sem fratura; Experimental 1 ( $\mathrm{n}=$ 10) - Modelos de gesso colados com adesivo a base de Cianoacrilato SuperBonder ${ }^{\circledast}$ (Loctite, São Paulo, Brasil) após fratura no espaço protético, entre os dois pilares; Experimental $2(\mathrm{n}=10)$ - Modelos de gesso colados após fratura horizontal nos pilares, simulando fratura ocorrida durante a remoção do modelo do molde; Experimental $3(\mathrm{n}=10)$ - Modelos de gesso colados após fratura simulando acidente de queda de uma bancada de laboratório.
Todas as unidades amostrais dos grupos experimentais e controles foram mensuradas com paquímetro digital de resolução $0,01-150 \mathrm{~mm} / .0005$ ".6" (Mitutoyo, Indústria Brasileira), na seguinte referência: distância externa entre o topo dos pilares (Fig. 2). Comparou-se as distâncias lineares do subgrupo controle com cada um dos subgrupos experimentais. As medidas foram executadas pelo mesmo operador e repetidas três vezes, resultando numa média para cada subgrupo. O processamento e a análise dos dados foram realizados através do programa SSPS ${ }^{\circledR}$ para Windows, versão 18.0.

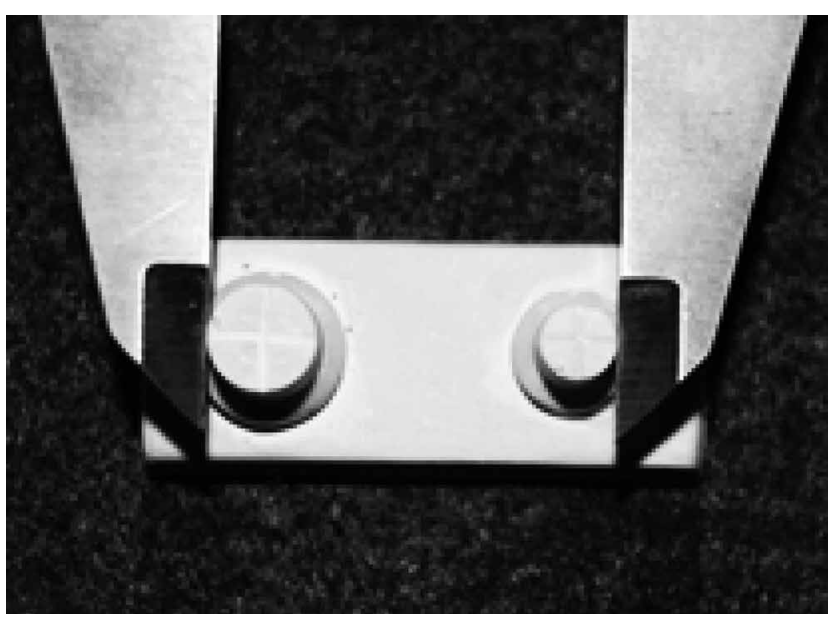

Figura 2 - Mensuração da distância entre pilares com paquímetro digital

Primeiramente, aplicou-se o teste de Shapiro-Wilk para avaliar a normalidade das variáveis. Para verificar a diferença entre as médias do subgrupo controle com cada subgrupo experimental, utilizou-se teste $t$ student pareado considerado estatisticamente significativo um valor de $p<0,05$.

\section{Resultados}

A Tabela 1 mostra os resultados mais significativos do estudo.

Tabela 1 - Comparação entre as médias $(\mathrm{mm})$ da distância entre pilares e valor de $p$ entre o subgrupo controle e os subgrupos experimentais dos modelos de gesso tipos III e IV

\begin{tabular}{|c|c|c|c|c|}
\hline \multirow{2}{*}{ SUBGRUPOS } & \multicolumn{2}{|c|}{ GESSO III } & \multicolumn{2}{|c|}{ GESSO IV } \\
\hline & Média & $p$ & Média & $\mathrm{p}$ \\
\hline Controle & 25,90 & & 25,79 & \\
\hline Experimental I & 25,91 & 0,833 & 25,97 & 0,000 \\
\hline Controle & 25,90 & & 25,79 & \\
\hline Experimental II & 25,99 & 0,031 & 25,96 & 0,002 \\
\hline Controle & 25,90 & & 25,79 & \\
\hline Experimental III & 26,01 & 0,008 & 25,92 & 0,004 \\
\hline
\end{tabular}

Teste t Student $(p<0,05)$ 


\section{Discussão}

Uma limitação a considerar no uso do cianoacrilato é a sua citotoxidade. Os cianoacrilatos de cadeia curta (etil e metilcianoacrilato) não são aptos para uso médico devido sua rápida degradação com emissão de produtos tóxicos. No entanto, os de cadeia longa (octil e butilcianoacrilato) se empregam amplamente em medicina nas diferentes especialidades, pois se degradam mais lentamente, gerando assim menor toxicidade ${ }^{8}$. Estudo mostrou que o etil-cianoacrilato, quando aplicado diretamente sobre a mucosa gengival com o propósito de fixar o dique de borracha em pacientes que necessitavam de tratamento endodôntico em dentes sem coroa clínica ou com essa severamente destruída, não causou genotoxicidade sobre o tecido mucoso se comparado aos resultados do grupo controle ${ }^{10}$. No presente estudo, diante da necessidade de colagem dos modelos de gesso na rotina do laboratório de prótese, avaliou-se o uso de cianoacrilato na colagem de fragmentos de modelos de gesso, uma das muitas aplicações desse adesivo na prótese dentária. Utilizou-se um etil-cianoacrilato (SuperBonder ${ }^{\circledR}$ ) de cadeia curta, mais tóxico que os de cadeia longa. No entanto, essa propriedade não foi levada em consideração, pois sua aplicação foi meramente laboratorial.

Estudo anterior avaliou a alteração dimensional de fragmentos de gesso tipo IV colados com cianoacrilato, em que as referências para as medições da precisão dimensional foram ranhuras transversais ao longo de uma placa de gesso e os resultados mostraram que o adesivo não provocou alterações dimensionais significativas ${ }^{3}$. Resultado diferente foi encontrado neste experimento, no qual os modelos de gesso fraturados e colados com cianoacrilato exibiram alterações dimensionais lineares quando comparados aos respectivos controles. Esse resultado pode ser explicado pela diferença dos corpos-de-prova utilizados. Neste experimento, os modelos simulam preparos de coroas totais de uma prótese fixa e na colagem dos pilares, devido a impossibilidade de padronizar a angulação com relação ao seu longo eixo, pode ter ocorrido a distorção, que neste caso se relaciona mais com a angulação do pilar no ato da colagem do que com o próprio adesivo. Pesquisa utilizando modelos de gesso de arcos dentados mostrou que houve alterações no momento da colagem dos dentes fraturados no que concerne à angulação desses ${ }^{12}$, em concordância com os resultados deste experimento que também apresentou alterações na colagem. Dessa forma, demonstra-se a semelhança entre colagem de dentes fraturados em modelos de gesso e colagem de pilares fraturados em modelos de gesso, ocasionando em ambos os riscos de distorções.

Os modelos de gesso tipo III do Grupo 1, em que a fratura se localizava entre os pilares, se comportaram de forma diferente quando comparados com os modelos de gesso tipo IV do mesmo grupo, não exibindo diferença estatística significativa. Isso talvez se justifique por ser o gesso tipo III mais poroso que o tipo IV, facilitando a embebição do adesivo, diminuindo assim a sua película. Estudo comparou a densidade de volume de poros nos gessos tipos III e IV e foi categórico ao afirmar que o gesso tipo IV tem menos volume de poros internos que o gesso tipo III que apresenta maior porosidade na sua estrutura ${ }^{13}$.

O tipo de fratura (espaço protético) do Grupo 1 também pode ter contribuído para reduzir a distorção a níveis não significativos, mesmo porque nas fraturas de pilares (experimental 2) e nas fraturas causadas por queda (experimental 3) os modelos de gesso tipo III exibiram alterações dimensionais semelhantes aos modelos de gesso tipo IV. Nesses grupos as fraturas foram mais complexas e comprometedoras que as fraturas entre pilares (no espaço protético).

\section{Conclusão}

Considerando as limitações do estudo e a metodologia utilizada, a técnica de colagem dos fragmentos de gessos tipo IV com cianoacrilato provocou alterações dimensionais significativas, sugerindo que esse procedimento deva ser contraindicado para modelos de trabalho que exijam precisão dimensional.

A colagem de pilares em modelos de gesso de prótese fixa, sem padronização, põe em risco a precisão dimensional desses.

\section{Abstract}

Objective: To assess the dimensional accuracy of gypsum models types III and IV, subjected to several types of fractures and followed by cyanoacrylate bonding. Materials and method: The sample consisted of 80 cast models made from Platinum Zetalabor ${ }^{T M}$ addition silicone dies from a master model in stainless steel, with two abutments. Two groups were formed ( $n=$ 40): Group 1 - Gypsum models type III, and Group 2 - Gypsum models type IV. Each group was subdivided by: Control $(n=10)$ - Gypsum models without fracture; Experimental $1(n=10)$ - Gypsum models bonded with Super Bonder ${ }^{T M}$ cyanoacrylate-based adhesive after fracture in the prosthetic space between two abutments; Experimental $2(n=10)$ - Gypsum models bonded after horizontal fracture in the abutments, simulating fracture occurred during removal of the die model; Experimental $3(n=10)$ - Gypsum models bonded after fracture simulating an accident of fall from a laboratory bench. The sampling units were measured using a digital caliper. Data were processed and subjected to statistical analysis (Shapiro-Wilk test, and Student $t$ test). Results: The gypsum models fractured and bonded with cyanoacrylate showed linear dimensional changes when compared to respective controls. The gypsum models type III from Group 1 behaved differen- 
tly when compared to gypsum models type IV from the same group. Conclusion: The bonding of abutments in cast models of fixed prosthesis without standardization threatens their dimensional accuracy.

Keywords: Gypsum. Dental Prosthesis. Cyanoacrylate.

\section{Referências}

1. Schwedhelm RE, Lepe X. Fracture strength of type IV and type V die stone as a function of time. J Prosthet Dent 1997; 78:554-9.

2. Hanson JG, Ettinger RL, Peterson LC, Rittman B, Scandrett FRet al: Effect on dimensional accuracy when reattaching fractured lone standing teeth of a cast. J Prosthet Dent 1982; 47:488-492.

3. Cardoso M, Torres MF, Lourenço EJV, Telles Dde M. Dimensional changes in gypsum fragments bonded with cyanoacrylate. J Prosthodont 2011; 20:470-3.

4. Ghahremannezhad HH, Mohamed SE, Stewart GP, Weinberg R. Effects of cyanoacrylates on die stone. J Prosthet Dent 1983; 49:639-46.

5. Lyon HE, Mitchell R. Abrasion resistance of coated gypsum dies. Oper Dent 1983; 8:2-5.

6. Lindquist TJ, Stanford CM, Knox E. Influence of surface hardener on gypsum abrasion resistance and water sorption. J Prosthet Dent 2003; 90:441-6.

7. Côrrea FG, Henke PG, Ferreira FV. Efeito antimicrobiano do cianoacrilato. Cardeno Odontol Clin 2011; 8(2):416-20.

8. González JM. Cianoacrilato. Definición y propriedades. Toxicidad y efectos secundários. Aplicaciones em medicina y odontología. Av Odontoestomatol 2012; 28(2): 95-102.

9. Pires-de-Sousa FCP, Contente MMMG, Casemiro LA. Cianoacrilato como protetor superficial de restaurações de cimento de óxido de zinco e eugenol e de cimento de ionômero de vidro: avaliação da infiltração marginal. Cienc Odontol Bras 2006; 9(1):47-53.

10. Araújo GG, Cavada LCM, Machado IG, Roth MGM, Formolo E. Avaliação da genotoxicidade do etil-cianoacrilato quando usado junto ao isolamento absoluto, através do teste do micronúcleo: um estudo in vivo. RPG: Rev Pós- Grad 2003; 10:141-7.

11. Damasceno LM, Portela MB, Primo LG, Damasceno FMB. Uso do cianoacrilato como auxiliar no isolamento absoluto: uma opção em odontopediatria. J Bras Odontopediatr Odontol Bebê 2003; 6(30):132-6.

12. Likeman P, Paolinelis G. An investigation of the accuracy of refixing broken teeth to stone casts. Eur J Prosthodont Restor Dent 2007; 15:127-30.

13. Moslehifard E, Nasirpourin F, Mahboub F, Salehjou M, Ghasemzadeh S, Bahari M. Influence of chemical disinfection on mechanical and structural properties of type III and IV dental stones. Adv Appl Ceramics 2012; 111:450-8.
Endereço para correspondência:

Carmem Dolores Vilarinho Soares de Moura Rua Miosótis, 1837, Bairro Jockey Club 64048-130 Teresina / PI

Fone: (86) 99212498

E-mail: carmemdvsm@uol.com

Recebido: 07/11/2013. Aceito: 18/03/2014. 